\title{
PERSPECTIVAS Y DUALIDADES PRONOMINALES (YO-TU) EN EL ROMANCERO ESPIRITUAL DE LOPE DE VEGA
}

E1 Romancero espiritual de Lope de Vega ${ }^{1}$, compuesto de romances incluidos la mayoría en sus Rimas sacras (I6I4), nunca fue escrito como libro. Salió en Pamplona en I6r9, según afirma el bibliógrafo Vicente Salvá, con el título de Romancero espiritual, para recrearse (en ediciones posteriores "reglarse») el alma en Dios, y redención del género humano... compuesto por Lope de Vega Carpio ${ }^{2}$. Carece de dedicatoria y prólogo. La edición príncipe, desconocida, fue reeditada de nuevo en 1624 por Juan de Oteyza, impresor del reino de Navarra. Le añade las "Estaciones de la Via Crucis», y en cada una de las quince estaciones, cuatro devotas consideraciones. Las sucesivas (y posteriores) ediciones del Romancero espiritual (Madrid, I673, 1720) no se enriquecen con "nuevas oraciones y ejercicios piadosos" como afirma

1 Véase Romancero espiritual y Rimas Sacras, edición, prólogo y notas de LuIs GuARNER, Madrid, I94I. Varias series sueltas de este romancero (los «Catorce Romances de la Pasión de Jesu Christou) se hallan en la The Hispanic Society of America, en Nueva York. Son a modo de minúsculos devocionarios de bolsillo, del tamaño de $16 \times 8 \mathrm{~cm}$., con diversas viñetas en sus portadas. Salieron de diversas imprentas: dos en Madrid, uno en I778; otro en Segovia (sin fecha); seis en Valladolid (uno sin fecha), lo que prueba la gran tradicionalidad de que disfrutó este romancero en tierras castellanas. La última edición es de r89o. Carecemos todavia de un estudio sobre la expansión de la poesia religiosa popular y sobre su influjo en la literatura del siglo XVIr, como bien sugiere MARfA CRUz GARcfa DE EnTERRfA, Sociedad y poesía de cordel en el Barroco, Madrid, r973. pp. I80-I8I.

- Véase la Colección de las obras sueltas, assi en prosa, como en verso, de D. Frey Lope Félix de Vega Carpio, del habito de San Juan, 21 vols, edición de don Antonio de Sancha, XV, Madrid, 1777, p. 443. Abreviamos eata colección con las siglas $O S$. 
Luis Guarner ${ }^{1}$; sólo varían de tamaño. La edición de 1673 es, por ejemplo, un pequeñico libro de bolsillo $(7 \times$ ro $\mathrm{cm}$.) que poseyó el marqués de Jerez de los Caballeros, y cuyo único ejemplar pasó a la colección de la The Hispanic Society of America, bellamente encuadernado con rosón en oro y sello de la identidad. La edición de I720 es la "cuarta» impresión, avisa en la portada el editor (Pedro Joseph Alonso y Padilla), pero «tercera» al final de la obra.

Incluye la primera parte dos romances dedicados a la Infancia de Jesús. E1 primero ("A1 Nacimiento de Christo», fol. 5) fue tomado de las Rimas sacras; el segundo ("La buena ventura del Niño Jesús», fol. 7), de los Pastores de Belén. La segunda parte, titulada "La redención del Cénero humano", está compuesta por veinte romances numerados (también incluidos en las Rimas sacras). Entre el romance noveno y décimo se intercalan las "Meditaciones» (fols. 33-77), que se componen de una breve oración y una meditación cuyo tema se introduce con una redon-

1 Anteriormente, en 1622, apareció una edición en Zaragoza que se cita en el tomo XIV (p. vi) de las OS, y en el Manuel du libraire et de l'amateur de livres, V, Paris, I864, p. I roga, de Jacques-Charles Brunet. Existe un ejemplar en la Biblioteca Vaticana. De la edición de Pamplona de I624 (al parecer la segunda edición de la de I6r9), la The Hispanic Society of America reprodujo una edición facsímil (New York, rgo3) que José F. Montesinos (ed. de las Poesias livicas de Lope de Vega, II, Madrid, I963, p. I70) cree ser la primera. La cuarta edición (Madrid, 1625) es la incluida en el vol. XV de las OS. Lleva aprobación de D. Juan de Xauregui y censura de Fr. Hortensio Félix Paravicino, buen amigo de Lope (pp. 445-446). Don Pedro Salvá y Mallen en su Catálogo de la Biblioteca de Salvá, I, Valencia, I872, p. I74b, afirma conocer la edición de Pamplona de I624 («en su posesión" escribe, la de Madrid de I625 y otras posteriores; tal vez las de I68o, 1720, I724). Salvá manejó un ejemplar, sin portada, que rezaba: «En Madrid, por Andrés García de la Iglesia. Véndese en casa de San Vicente, enfrente de San Felipe, S. A." (hacia I680) y describe su formato. Tiene también presente otra edición impresa sin duda en "Madrid, A costa de Juan de S. Vicente, Librero enfrente de S. Felipe, con $24^{\circ}$, y 250 folios" ("quizá fueron páginas", añade Salvá), concluyendo que debe pertenecer "a la última mitad del siglo xvII". Afirma Salvá expresamente que el texto de la aprobación del libro, que data del 26 de julio de I6rg, fue el que pasó a la edición de I624. La portada "Hánse añadido en esta impresión" supone una anterior. El bibliógrafo Antonio Nicolás (Bibliotheca Hispana Nova, II, Madrid, I788, p. $78 \mathrm{~b}$ ) indica el hecho de que muchos de los romances incluidos fueron publicándose, como ya hemos indicado, independientemente, en pliegos sueltos. Véase LUIS GUARNER, Autenticidad y critica del «Romancero espiritual de Lope de Vega y La cuestión bibliografica referente al "Romancero espiritual de Lope de Vega, en Revista de Bibliografia Nacional, III, Madrid, 1942, pp. 64-79 \& 198-207, respectivamente. 
dilla que las precede ${ }^{1}$. La tercera parte consta de diez romances, dedicados unos a la Eucaristía (una "villanesca»); otros, de carácter más narrativo (heroico-caballeresco), a varios santos: San Ignacio, San Francisco de Asís; además, una "canción", un "soliloquio" y un pastoril "edilio". Considera Angel Valbuena Prat los romances de Lope en torno a la Pasión del Señor como «los romances más bellos y plenamente logrados, sin retórica de modas pasajeras", concluyendo: "E1 Lope de los 'soliloquios' y de los 'romances' y aun de algunos sonetos, a pesar de la métrica culta que suponen - relativamente culta-, son los mayores aciertos del poeta religioso y acaso de toda su obra subjetiva" 2 .

Sin embargo, las estructuras narrativas como las del romance, objetivo, directo, no subordinan términos ni razonan causalidades filosóficas: relatan con vividez y coordinan elementos; establecen contrastes y oposiciones semánticas. Pero un rasgo peculiar del Romancero espiritual de Lope de Vega es que, al narrar éste la historia del Crucificado (épica y lírica a lo divino), lo hace en términos coloquiales, si bien cargados de intensa emotividad y dramatismo ${ }^{3}$. Su actitud de narrador comprometido con la materia narrada, al igual que el empleo de varios elementos retóricos, propios de la oratoria sagrada, realzan su carácter patético. No se esclarecen misterios dogmáticos, ni se contrastan situaciones paradójicas (Dios-Hombre; la Trinidad-una; la Virgen-Madre). Se aprehenden emotivamente a base de símiles tomados del vivir cotidiano, pero reducidos a planos concretos y tangibles.

1 Se exhorta en ellas al alma a que contemple algún detalle doloroso o injusto de la pasión: "Considera, alma perdida, / que en aqueste paso fuerte / se dio sentencia de muerte / al Redentor de la vida" ("Primera estación»). A cada redondilla le sigue una glosa en prosa, concluyendo con una "meditación". A veces entre ambas se inserta una voración" (estaciones I, XIII, XIV, XV). Las "Meditaciones de la via-Crucis» se incluyen en las $O S$ (XV, pp. 453-486), al igual que el "Coloquio entre San Juan y el Niño Jesús", bajo el titulo general de "Contemplativos discursos" (pp. 455-464), y la "Forma breve de rezar" (pp. 485-500). Consta este poema de cincuenta sextinas, divididas en cinco grupos de a diez, introducidos cada uno por un "Pater noster". Trata sobre los diversos aspectos de la vida de Cristo. Concluye con una letania, un acto de contrición y con las Estaciones del cordón" (fols. 7 I-77).

- Anger Valbuena Prat, La religiosidad popular en Lope de Vega, Madrid, 1963, pp. 28 y 29.

8 «En resumen: el dogma que es el más allá divino no interesa, se busca la lágrima, el estado emotivo que es de este mundo", expresa Josł ORTEGA y GASSET, Obras completas, V, Madrid, I958, p. 149. 
La secuencia narrativa de la mayoría de los romances es gradual y ordenada: ubicación espacial, presentación de un diálogo entre la Virgen y Cristo, o éste y un apóstol, y exhortación final o acto de contrición. El narrador, impersonal, si bien vidente, se dirige al alma, a quien acompaña. En la graduación narrativa, con frecuencia climática, se despliegan series de símbolos, símiles, emblemas y continuas referencias bíblicas, topos comunes de la lírica religiosa; temas de sermonarios, libros de devoción y de catecismos de la época.

Los desdoblamientos que se establecen entre el narrador impersonal y el tú-alma, con la que se identifica al final de los romances ("alma... a acompañarla volvamos»; "decidle»; "volved a la Virgen Santa»; "no seas tan dura»; "alma, llorad y tened / lástima de ver que azotan»; "perdonaremos»), incluyen en dichas interferencias a un espectador cómplice (cualquier pecador) responsable también del estado en que se encuentra Cristo. Este se sitúa con el narrador al exterior del cuadro (o paso). descrito. Pero el narrador, conmovido a su vez por los hechos que presencia, toma también parte activa en la escenificación: exhorta al alma ("túi) a que considere compasivamente el cuadro visto (o descrito). De este modo se va variando la posición estática del comentador (y su perspectiva), y éste se sitúa alternativamente: en el exterior, con el espectador (pecador a la vez), y en el interior como testigo y como narrador. Este describe y es voz que gứa la meditación penitencial (activo); se agrupa a la vez con el grupo de los pecadores y con ellos se humilla y se arrepiente (pasivo). Pero el espectador, exterior e impersonal, situado con frecuencia en un plano más bajo, es objetivo, impasible, neutro; el interior, por lo contrario, se siente responsable de los hechos cometidos: simpatiza con Maria en su soledad o con Cristo en su dolor. Instalado en el exterior acompania al resto de los penitentes; situado en el interior del escenario es contrito pecador. El doble cruce de perspectivas se establece a base de la fórmula pronominal "tú-alma», desdoblada en varios casos en la dualidad vocativa "nosotras-almas». La movilidad del narrador, al pasar de situaciones exteriores a interiores ("tú-nosotros»), al igual que al usar variadas fórmulas exclamativas y vocativas (exhortación, apóstrofe o exhortación y apóstrofe), compromete a la vez al lector. Dicha técnica (fórmulas exclamativas, exhortativas, rogativas; figuración visual, táctil, representativa) es parte del proceso imaginativo ignaciano, que implica la consideración del hecho histórico, la situación espacial (ubicación) y la conmoción personal ante las propias culpas: doblaje interior y teatral, presente en los 
Ejercicios espirituales de San Ignacio y en los libros de meditación. Proceso que va del acto de contemplar una situación imaginada al hecho de convertirla en plegaria; en acto de contrición.

E1 primer romance, titulado "A la despedida de Cristo nuestro bien de su madre Santísima" (Romancero espiritual, fol. II) ${ }^{1}$, presenta la estructura descrita. Comienza el romance ubicando, primero, el hecho bíblico: la madre se despide del hijo camino éste del Gólgota. Desarrolla luego un diálogo (apócrifo e imaginativo) que se convierte en soliloquio alternante entre la Virgen y el Hijo, concluyendo, al final, con una exhortación dirigida al alma: «llega y dile: 'Virgen pura / iQueréis que yo os acompañe?'». El mismo modelo narrativo se halla presente en el romance "Al lavatorio del falso Apóstol» (fol. I4). El diálogo es sustituido en este romance por un extenso monólogo interior que Cristo ("entre sí le dice») dirige a Judas. E1 narrador, exterior e impersonal en las primeras líneas ("Besando está Jesucristo / de un hombre infame los pies»), se introduce dentro del cuadro al dirigir él mismo la palabra a Jesús: "No lavéis más estas plantas, / piedras son, que no son pies», continuando: "Quitad la boca, Señor, / De ese bárbaro infiel, / Y esas manos amorosas / En nuestras almas poned». E1 narrador inicial, distante e impersonal (tercera persona), se agrupa ahora con el conjunto de los espectadores («nuestra alma»: primera persona), identificando al "túalma" (segunda persona, singular). Estructuras lingüísticas fijan los varios paradigmas poéticos creando un doblaje de perspectivas (teatrales $\mathrm{y}$ escénicas) y alusiones pronominales: del narrador que es mero testigo al narrador que se identifica como pecador; éste como alma condolida. Pero al variar dichos enfoques (alternantes y reversibles) se incrementan los elementos emotivos, considerándose el mismo cuadro bajo diferentes posiciones y planos (alto, bajo); distancias (lejos, cerca) y a través de dobles espectadores ${ }^{2}$ : del "yo he sido" pecador al "alma»

1 Seguimos la edición facsímil de la The Hispanic Society of America. José Manuel Blecua incluye diecinueve romances de la Pasión en la edición de las Obras poéticas, I, de Lope de Vega (Barcelona, I969), pp. 4I4-455. Un buen número de ellos se agrupan en el vol. XIII de las OS (pp. 276-330), y José F. Montesinos incluye un manojuelo en su ed. de la Poesía livica de Lope (vol. II).

- Roman Jakobson pasa libremente de la estructura lingüistica de un paradigma a las categorias poéticas al afirmar: «Epic poetry, focused on the third person, strongly involves the referential function of language; the lyric, oriented toward the first person, is intimately linked with the emotive function; poetry of the second person is imbued with the conative function and is either supplicatory or exhortative, depending on whether the first person is subordinated to the second one or the second to the first" en "Concluding Statement: Ininguistics and Poetics", incluido en Style in Language, ed. by ThOMas A. SzBBoK, New York. 1960, p. 357 . 
("tú») arrepentida ${ }^{1}$. La misma técnica la muestran los romances "A la Prisión" (fol. 20) y "A los Azotes» (fol. 23). Un narrador impersonal inicia el primer romance. Se describe el bofetón que Cristo recibe de un soldado $\mathrm{y}$, después de dirigirse a la Virgen, se identifica él mismo como pecador (upues siendo los hierros míos, / quieres tú tener los clavos»).

Los mismos romances "Al entierro de Cristo" (fol. 94) y "A la soledad de Nuestra Señora" (fol. 97) ofrecen idénticas estructuras. En el primero, el narrador realza el agudo dolor de la madre. Cristo yace muerto en sus brazos, identificándose ésta como cruz clavada. A la madre ("muerta en Cristo») se acercan los venerables ancianos a pedirle el cuerpo del hijo para darle sepultura. El profundo dolor rasga su corazón en telas (al igual que las del templo) ${ }^{2}$ sirviendo de enlutada mortaja. Y ocurren hechos maravillosos: «las cajas fueron las piedras, / Unas con otras sonando" ${ }^{3}$. Pero el mismo narrador, conmovido, participa también en el cuadro descrito, transmutando de nuevo espacios $\mathrm{y}$ enunciaciones pronominales. Se introduce en la escena, y como compañero del alma, le pide:

\section{Alma, la Virgen se vuelve, $A$ acompañarla volvamos \\ Pues con ella volveremos $A$ verle resucitado.}

1 Los pronombres y demostrativos, afirma Paul Ricoeur, "designan con mucha proximidad, lo absoluto de esta posición y de esta demostración, que son el más acá y el más allá del lenguaje: el más acá personal de donde procede el lenguaje como acto de habla, el más allá mundano hacia el cual se dirige, en cuanto dice algo sobre algo. Asi como no es objeto, el lenguaje tampoco es fundamento; es mediación; es el medium, el medio en el cual y por el cual el sujeto se coloca y el mundo se muestra». Véase Estructura, palabra, acontecimiento en Estructuralismo y lingüistica, Buenos Aires, 1971, p. 85: EMIIE BENVENISTE, Problemas de lingǘstica general, México, 1974, p. I6I-178.

- La misma imagen fue usada en el Mio Cid al describir, en el «Cantar de Corpes", la gran pena de Félez Muñoz, al encontrar a sus primas, doña Elvira y doña Sol, exánimes y brutalmente azotadas por los Condes de Carrión: «Partiéronsele las telas de dentro del corazón / llamando '?Primas, primas, don Elvira y doña Soll'». Don Ramón Menéndez Pidal documenta más frases sinónimas en el Mio Cid: «descubrir a uno las telas del corazón (ver. 3260); "tajábales las telas» (Alex., vers. 704). Ya en el Mio Cid está usada la frase como término de cariño ( (las telas del corazb́n", vers. 2578) al igual que en El Quijote (II, 13).

- Diego GutitrRez DE Certina, Poesias manuscritas recopiladas de varios (1577) expresa: "Hiere una piedra en otra con gran duelo / La tierra con angustia se estremecen. Véase en Romancero y Cancioneros sagrados, ed. de JUSTO DE: SANCHA, col. $B A E$, vol. XXXV, Madrid, 1884, p. $46 \mathrm{~b}$. En adelante abreviaremos esta colección con las siglas $B A E$, seguidas del número del volumen. 
Tales esquemas (situación espacial; diálogo o monólogo; exhortación o súplica) modulan la narratología plástica de este Romancero en conjunción con las prácticas meditativas de San Ignacio. La memoria recuerda el hecho histórico (tiempo + espacio); la imaginación lo acerca y le da vida escénica (diálogo + monólogo), y la voluntad (exhortación, súplica) aplica la enseñanza en resoluciones ascéticas ${ }^{1}$.

E1 romance "A la soledad de Nuestra Señora" describe, a base de un simétrico esquema de hipérboles superpuestas, la soledad de Maria. La preposición privativa "sin", repetida en once casos, realza en el núcleo inicial de cada verso, esta soledad física y trascendente: «sin esposo, sin padre, sin hijo, sin luz, sin voz, sin alma, sin cuerpo, sin tierra, sin aire, sin fuego, sin agua». En el segundo núcleo, once enunciados paralelos establecen la causalidad del primer grupo: "Porque estaba", "porque se esconde", "porque está muerto", "porque llora el sol", "porque muere el Verbo", "que todo es sangre", "que todo es fuego", "que todo es agua", "que todo es hielo" ("ausente la suya", "enterrado el cuerpo"), equilibrando de este modo los términos negativos precedentes. La correlación, diseñada a base de estructuras antitéticas o complementarias, contrasta los elementos vertical y horizontalmente:

Sin esposo, porque estaba
José de la muerte preso,
Sin Padre, porque se esconde,
Sin Hijo, porque estd muerto:
Sin luz, porque llora el Sol,
Sin voz, porque muere el Verbo,
Sin alma, ausente la suya,
Sin cuerpo, enterrado el cuerpo,
Sin tierra, que todo es sangre,
Sin aire, que todo es fuego,
Sin fuego, que todo es agua,
Sin agua, que todo es hielo.

La Virgen sin el hijo: sola. Emotivamente el narrador ha penetrado, a base de circunloquios y paradojas, aliteraciones y anáforas, el escenario que ocupa la madre. Los términos negativos se explican o reafirman con sus consiguientes positivos («sin aire, que todo es fuegou), alternando simétricamente las correspondencias cósmicas de los elementos. Al final, el narrador introduce a la Madre quien, "con divino esfuerzo", lamenta la muerte del hijo. El "Dijo la Virgen Maria" y las

1 Lours I. Mariz, The Poetry of Meditation, New Haven, 1962, pp. 26-39, 57 . 
"quejas lastimosas» cierran la alocución dirigida a la cruz, con quien se identifica: la madre sin el hijo; la cruz sin su dueño. Concluye el romance ${ }^{1}$ :

\author{
Corazón de piedra dura, \\ Quedad llorando deshecho, \\ Que la muerte de Dios hombre \\ Las piedras parte por medio.
}

La fórmula exhortativa identifica al narrador que inicia el romance con el que, vocativamente, pide se conduelan de la Virgen. Pero no todos los romances establecen la misma dualidad pronominal. En «A1 santísimo Sacramento" (fols. I 3V-I4V) el yo se identifica en la primera línea al expresar: "Hoy por esclavo me escribo». El mismo soliloquio a la eucaristía es una fórmula de adoración y de fe ante el dogma divino: "Pan cuerpo de Cristo». En el romance "Al ponerle en la Cruz» (fols. 78r-8or) el narrador describe los actos cruentos del expolio de Cristo, e insiste en la crueldad de los soldados, dirigiéndose al mismo tiempo al alma para que se conduela ante el cuadro descrito. Se introduce en el escenario narrado con fórmulas exclamativas y de asombro. Ya en Francisco de Osuna, en varias de sus meditaciones incluidas en el Abecedario espiritual (I525-I554), por ejemplo, en la dedicada a los "Azotes", el narrador es guía textual del lector. Este irá repitiendo el texto, identificando, en el mismo acto, lectura e inscripción gráfica, figurativa y plástica. Y Fray Luis de Granada en su Libro de la oración y meditación lograba la comunicación directa con el lector a base de continuas exhortaciones. La intención era colocar al lector en un ámbito espacial y emotivo; introducirlo dentro como elemento de atrición viendo y participando en la representación.

$\mathrm{Y}$ si bien a los romances analizados e incluidos en la "Segunda parte» le corresponden las mismas estructuras, en «El alma a Cristo en la Cruz», "A las lágrimas y arrepentimiento del alma», "Del alma a su esposo Cristo", "A la oveja perdida" y el idilio "Al alma pecadora", lo mismo

- Dichas imágenes, al igual que la de Lignum crucis, se extendieron a través de himnos religiosos populares. Al himno "Dulce Lignum" hace referencia Venancio Fortunatus en su himno "Pange, Lingua", lo mismo que el himno anónimo que empieza "Laudes crucis attolamus" (The Penguin Book of Latin Verse, London, 1962, pp. 125, 185). A la cruz como árbol y a Cristo como cordero pendiente de un madero alude Fray Pedro de Padilla en su Jardin espiritual; en concreto, en el romance "A la muerte de Cristo, Nuestro Salvador" ( $B A E, \mathrm{XXXV}$, pp. 92b93a), lo mismo que el soneto de don Cristóbal de Villarroel, incluido en Flores de poetas ilustres de PEDRo Espinosa (BAE, XXXV, p. 49b). 
que la canción "En alabanza del Esposo del alma»" ${ }^{1}$ los elementos líricos sobreabundan sobre los narrativos. En el primer romance, el alma, arrepentida y situada al pie de la Cruz, rompe en amargo llanto al considerar las llagas de Cristo. El mismo carácter lagrimoso está presente en los romances "A las lágrimas y arrepentimiento del alma" y "Del alma a su esposo Cristo». Un romancillo final acentúa la tonada coral. Por ejemplo, en «Del alma a su esposo Cristo» la alegoría esposa-esposo estructura la semántica de la composición. Las lágrimas se convierten en cartas de amor; en símbolos de condolencia y de fidelidad.

Como enamorado pastor en busca de su oveja perdida presenta Lope a Cristo y al alma en el romance "A la oveja perdida". El paisaje evocado corresponde al locus amoenus de la tradición pastoril. En el "Edilio al alma pecadora" (Romancero espiritual, fol. II7) la alegoría del alma descarriada se establece en términos de serranas, pastores y cortesanos, presentes en las "trovas" del Marqués de Santillana. Un pastor de "rara belleza" desea enamorar a la serrana (el alma). Los términos "pastor" (Cristo), "cabaña" (altar), "pan" (eucaristía) establecen los dos niveles alegóricos. Hallada la oveja se celebra el divino epitalamio: "Echóle los brazos. / Fuéronse a la Iglesia, / Y los serafines / Cantando con ellan. Funde aquí Lope la tradición de serranas, serranillas y cantares del siglo xvi con las alegorías de los Autos sacramentales del siglo XVII.

Mas la misma efusión de júbilo la revela la canción "En alabanza del Esposo del alma». El estribillo, repetido simétricamente, define su carácter musical, otorgándole un aire de mágica ensoñación. Alegre el esposo de encontrar a su amada, es recibido en la alborada por el cantar de los ruiseñores:

\author{
Cantad ruiseñores, \\ Al alborada, \\ Porque viene el Esposo \\ De ver al Alma.
}

El enamorado vaquero pasó toda la noche rondando la casa de su serrana. Disfrazó su sayo de "color de nácar» y lo rebozó con "capa blanca», sugiriendo un ambiente de suspensión cósmica: "Escuchad las señas, / Aves sagradas». La misma configuración anatómica del rostro del amado es comparada, en sus partes, con lo más exquisito de la naturaleza: los cabellos son "plata de puro rocio"; "matiz de granada" su rostro; sus ojos "roban las almas», y sus labios semejan a los lirios. Las palmas,

1 Véanse folios I00, I10, I12, II5, II7, 122. 
aunque rotas (perforadas por los clavos), «jacintos y cielos" eran. A la choza de la serrana, ya entrada la noche, llega el "amoroso Cristo". Ella lo abraza, le lava los pies $y$ en íntimo idilio pasan la noche:

\author{
Fn dulces requiebros \\ La noche pasan \\ ¿Dichosa la prenda \\ que Dios regala!
}

Reincide sobre todo el Romancero espiritual en el dolor de la Madre, quien acompaña a su hijo camino del Gólgota. A la soledad de ambos hacía referencia San Ignacio en sus Ejercicios espirituales ${ }^{1}$. En el romance "Despedida de Cristo a su madre» ésta se declara corredentora al expresar: "vuestra cruz llevo en mis hombros". La separación de madre e hijo es ineludible; abrumador su dolor: quien se ausenta es Dios. Sin embargo, ambos están vistos en términos familiares de amantes e indefensos esposos.

Describe en el romance "A la Prisión" (fol. 20) el brutal bofetón que Cristo recibe de un soldado, al responder aquél a las preguntas que le hacía el Pontifice Anás (Io. 18, 22-23). El narrador pide a la Virgen (y elípticamente al lector) considere los labios de Cristo «a quien vuestra leche distes / Todos de sangre bañados", y a kaquellos hermosos dientes / al fiero golpe temblando". Se contrasta la ternura del pecho materno con la fiereza del puño; la amarga hiel con la "blanca leche». La imagen realza dos esferas semánticas que asocian los vocablos "leche" y "sangre»; "puñetazo brutal" y "pecho débil".

A la crucifixión física del Hijo corresponde la simbólica de la Madre, Se expresa su dolor a base de un término biológico ("entrañas") y otro

1 San Ignacio pide en sus Ejercicios espirituales (tercera semana, primer día, quinto punto) que se considere icómo la divinidad se esconde, es a saber, cómo podria destruir a sus enemigos, y no lo hace, y cómo dexa padescer la sacratísima humanidad tan crudelisimamenter. Al igual que en los romances espirituales de Lope, cada ejercicio de San Ignacio concluye con una decisión, originada por una conmoción previa del ánimo (patetismo jesuita). En ellos ve Jose Luis Aranguren wel advenimiento del hombre moderno y de la conciencia de si mimon en Catolicismo y protestantismo como formus de existencia, Madrid, 1963, pp. 142-157. 
espiritual y psíquico («penas») ${ }^{1}$, condensando en ambos múltiples alusiones culturales y líricas. Conmociones cósmicas, narradas en los evangelios (Mt. 27, 45; Mc. 15, 33; Luc. 23, 44-45) anuncian la muerte de Cristo. La naturaleza simpatiza con el dolor de la madre y con la muerte del hijo. En el romance "Al Ecce Homo" (fol. 28) Pilato presenta a Cristo ante el pueblo judío, al poco de ser azotado. A su sangre se une la luz solar apareciendo el sol teñido. Lo mismo sucede con el romance "A Cristo en la cruz" (fol. 83): el sol se cubre "sangriento de esmalte». Y en el "Al Entierro de Cristo» (fol. 94) el luto es cósmico:

\author{
Sol, y luna sangre visten, \\ Porque el cielo en tanto agravio, \\ Mostró sangre en sus dos ojos \\ Para señal de vengarlo.
}

En los romances pastoriles de Lope ("E1 lastimado Belardo", "E1 tronco de ovas vestido", "Al pie de un roble escarchado", "Cuando las secas encinas", etc.) ${ }^{2}$ la naturaleza era neutra; impasible con las penas del pastor. En el Romancero espiritual se conduele, por el contrario, del nefasto destino del héroe: Cristo. Las piedras, símbolo de dureza y de reciedumbre, se rompen unas con otras en señal de duelo, y la oración de Cristo en el huerto de Getsemaní las mueve a compasión, pues: «a penas de Dios las peñas / Saben hacer sentimiento" ${ }^{3}$. En el romance "A los azotes" (Io. I9, I-5) el mármol se ablanda y "cera se quisiera hacern, y en el que se narra la soledad de la Virgen, la exhorta-

1 El romance "Al bajar de la cruz" (fols. 92r-94v) se inicia de este modo: "Las entrañas de Maria / Con nuevo dolor traspasan / Los martillos que a Jesús / Del alta Cruz desenclavan". A las "virginales entrañas" alude el romance "A la Cruz a cuestas" (fols. 3or-32r). Los clavos que van clavando las manos de Cristo atraviesan las entrañas de Maria, y los golpes de los martillos van cayendo también en ellas ( Al levantarle en la Cruz", fols. 8ov-82v).

- Véanse el primer romance y el cuarto en el Romancero general (1600, 1604, I605), ed. de A. Gonzír, Palzincia, Madrid, 1947, II, núms. 806 y 855; los otros dos en Las fuentes del Romancero general de I600, ed. de A. RoDRfGUEZMoñino, Madrid, 1947, I, fol. 29 y V, fol. 29.

- Al mismo motivo bíblico le dedica un romance Juan López de Ubeda ( $B A E, \mathrm{XXXV}$, núm. 239, pp. 86a-b). A la dureza de las piedras en relación con la dureza de los hombres hace referencia Quevedo en sus sonetos en torno a la Pasión, lo mismo que Ledesma. Para ambos la piedra adquiere dualidad semántica: como objeto inorgánico (aventaja en ternura al corazb́n del hombre) y como basamento teológico ( $\mathrm{E}$ t ego dico tibi, quia tu es Petrus, et super hanc petram aedificabo ecclesiam meam, (Mt. I6, 18). 
ción final se dirige al "corazón de piedra dura», símil usado en el "Soliloquio VI" de Lope ${ }^{1}$.

Las escenas que describen con detalle el castigo que Cristo recibe, constituyen, por su naturaleza descriptiva, un agudo martirio para los sentidos. Camino del Gólgota repetidas veces cae Jesús con la cruz:

Cayó Cristo, y por la frente
Con el golpe desigual
Se le entraron las espinas
Lo que faltaba de entrar.
Cególe el polvo los ojos,
Si el Sol se pudo cegar,
La boca llena de sangre
Se estampó en un pedernal.

En el romance "Al levantarle en la cruz» percibe el oído el golpe seco de la cruz al caer en el hoyo. Observa la vista los movimientos; la sangre manando de la cabeza; el rostro ensangrentado. $Y$ el narrador le pide al espectador que participe en el expolio (consagrado por E1 Greco) para aliviar de algún modo el dolor divino: «Poned, alma, el corazón / si llegar a Cristo os dejan, / entre la Cruz y la mano / porque os le claven con ella».

Dos espacios, uno próximo, otro lejano, se establecen en las primeras estrofas del romance «A Cristo en la cruz». Ocupa el espectador el más próximo (inferior), y desde él observa lo que sucede en el lugar lejano (espacio superior), establecidos ambos con la enunciación interrogativa:

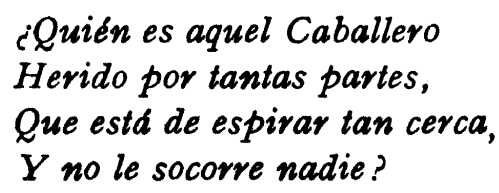

E1 desciframiento de las letras colocadas en lo alto de 1a cruz; la alusión a los dos ladrones; la oscuridad de la tarde y la presencia de María y Juan al pie del crucificado, acercan al espectador hacia «aquel $\mathrm{Ca}$ balleron. Ya más próximo, describe con fino detalle el dolor de los tres amantes: Cristo, María y Juan. La técnica narrativa, al igual que la plástica del Barroco, dobla espacios al igual que fondos ${ }^{2}$. De lejano

1 Soliloquios amorosos de un alma a Dios (OS, vol. XVII).

- Josk OrTega y Gasser, Sobre el punto de vista en las artes, en Obras completas, IV, Madrid, 1957, pp. 452-453. 
observador el narrador se convierte en cercano y compungido testigo, compartiendo con sus lágrimas el dolor de Cristo.

Figuras retóricas (interrogatio, admiratio, exhortatio) encadenan la andadura narrativa del romance "Al levantarle en la cruz». En "Al Ecce Homo" establece Lope series de admiraciones que realzan el estado de Cristo azotado. Este afán de considerar todos los rasgos del espectáculo («madero»; heridas, movimientos, contorsiones) es parte de la preceptiva retórica de la predicación religiosa de la época; de la "crueldad devota" a la que Ludwig Pfand hace referencia ${ }^{1}$. Ya el Santo Maestro Juan de Avila practicaba la descripción minuciosa (detallada), admirativa a las veces, en su $A u d i$, filia, que Lope comenta en el romance "A la corona» ${ }^{2}$.

Humor y realidad cotidiana caracteriza al romance dedicado a Dimas (Luc. 23, 4I-43), el buen ladrón. Una llamada de alarma avisa a los ángeles de la guarda para que tomen las armas y corran hacia las puertas del cielo: Dimas quiere robarlo. La puerta ("Cristo") ha sido rota por tres hierros, y con la llave bañada en sangre ("engrasada») se podrá fácilmente descorrer la cerradura. E1 ladrón, acechando por "los mismos agujeros", tantea por ver "si a la casa del tesoro / a Dios puede dar un tiento». Se desarrolla el romance de acuerdo con la estructura alegórica basada en la teología de la Redención, pero realzando a la vez la acción picaresca a lo divino. Este ladrón quiere «dar un tiento» al cielo. Se compara dicha "mansión" en términos familiares ("presidio eterno») la cual contiene fabulosas riquezas. Sus muros son de diamante. Con "ganzúas de fe" se acerca Dimas al "escritorio» del Verbo. Allí guarda éste sus joyas. Desea robar el cáliz lleno de sangre y la custodia de «su mayor sacramenton. Como vemos, la alegoría se relata en términos conversacionales $^{3}$ : el ladrón asalta el cielo en el momento en que la

1 Historia de la literatura nacional española en la Edad de Oro, Barcelona, 1933, p. 243.

2 El título del tratado de San Juan de Avila es Avisos y reglas cristianas; el subtítulo hace referencia al salmo de David, "Audi Filian, (Ps. 44, II). Sobre las influencias de San Juan de Avila en la lírica religiosa de Lope, véase MANUEL, DE MonToLfu, El Beato Juan de Avila y Lope de Vega, en Misceldnea Filológica, II, Barcelona, 1960, pp. I55-I 58.

3 Dicha concepción neopagana de la divinidad es topos, frecuente en el siglo xvir. A. CASTro y HUGo apuntan en la Vida de Lope de Vega (Salamanca, 1968, p. I37, nota 23, el siguiente ejemplo (kentre muchos") tomado de Fray Luis de Azevedo, de sus Discursos morales en las fiestas de la Reina del cielo, Valladolid, 1600, p. 7: "Dice el texto sagrado que se venia Dios paseando por el Paraiso, gozando de la marea blanda y aire suave que corria... $Y$ en aquel paseo daba a entender cuán recto juez era, que para tomar residencia no venía alborotado. 
casa está descuidada; es decir, ahora que Cristo yace muertoen la cruz ${ }^{\mathbf{1}}$. En el romance "Al levantarle en la Cruz» la alegoría se establece en términos bíblicos. El alma (esposa) está enferma y por ella Cristo (esposo) guarda cama. Con la esposa camina el narrador a visitarle pues dulcemente Cristo se queja. Las correspondencias de la tradición mística (Cristo-esposo; alma-esposa) figuran frecuentemente en este Romancero, al igual que las figuras abstractas de los Autos Sacramentales. El capitán del ejército que viene a prender a Cristo es la Envidia; su alférez, el Engaño. Los emblemas Cristo-cordero ( $A$ gnus-Dei) figu$\operatorname{ran}^{2}$ en referencia al sacrificio de Isaac (Gen. 22, 9-I3) y a la Pascua Judía $^{3}$, fundiéndose los términos pastoriles con los religiosos. Dicha fusión se llevó a cabo en el libro del Desseoso (nombre del protagonista en la versión catalana de $\mathbf{I}_{5} \mathbf{5}$ ), titulado en castellano Espeio de religiosos (I533), antecedente que López Estrada relaciona con los libros de pastores, y que mantuvieron en sus primeras manifestaciones, y después también en su desarrollo, una determinada condición espiritual, si bien vertida al campo de la profanidad literarian

Las metáforas en torno a la cruz están tomadas también de fuentes bíblicas. La cruz es escala (figura ésta en el sueño de Jacob) para su-

ni metido en cólera; y en venir después de mediodía, cuando los hombres suelen estar contentos, y tratan de sólo lo que es gusto y pasatiempo que... le era negocio gustoson.

1 La idea de Cristo portador de un gran tesoro (mperulero ricon) que desembarcó en las Indias y es uportador de joyas de valor inmenso", deseoso además de que se las roben, está expresada por ALONSO DE LEDESMA en sus Conceptos espirituales ( $B A E, \mathrm{XXXV}$, núm. 277, p. r03a). El hombre como ladrón de estas riquezas lo expresa Valdivielso en su romance "A la soledad de Nuestra Señora" (Ibid., núm. 28r, pp. I04b-105a). Con idéntico título escribe Lope un romance al que ya hemos hecho referencia.

- Al mismo emblema bíblico alude el romance "Al Ecce Homow. Al cordero de Abraham que espera el cuchillo (Gen. 22, I3) hace referencia Lope en A la Corona" (Rom. esp., fols. 25v-27v); al "cordero casto" y al "cordero manso" alude en IEl alma a Cristo Nuestro Señor en la cruz" (fols. Ioov-ro3v). El soneto de las Rimas sacras "Pastor que con tus silbos amorosos" se contamina con el tema del Buen Pastor clavado en la cruz, expuesto anteriormente por San Juan de Avila en su Tratado de amor de Dios para con los hombres (cap. VI, "La locura de amor"), y Fray Diego de Estella (1524-1578) en sus Meditaciones del amor de Dios (meditación decimoctava). Sobre emblemas religiosos véase MARIo PRAz, Divina Amoris Emblema, en Studies in Seventeenth-Century Imagery, Roma, 1964, p. 202.

- Véase Ex. I2; 13, 3-10; Lev. 23, 5 y ss.; Luc. 22, 15 y ss.; I Cor. 5, 7-8.

- Francisco ISPEZ ESTrada, Notas sobre la espiritualidad española en los Siglos de Oro, Sevilla, 1972, pp. ro y 27 , y en su reciente libro, Los libros de pastores en la literatura espantola, Madrid, 1974, pp. 281-322 y 478-516. 
bir al cielo ("Al bajarle de la cruz», fol. 92); es mesa sobre la que estuvo el pan atravesado "en el leño» ("A la soledad de Nuestra Señora»); es árbol; la Virgen huerto que lo recoge. Si María es mar, Cristo es su fuente; si ella la "sola del sol difunto", él trigo (pan eucarístico) de zarzas rodeado. A la alegoría del pastor y su oveja alude el romance "El alma a Cristo Nuestro Señor en la Cruz", quien desde lo alto llama con silbos a su ganado perdido ${ }^{1}$, y con su sangre (pelícano) reclama a sus polluelos ${ }^{2}$.

\section{III}

Incluye la "Tercera parte" del Romancero espiritual varios romances dedicados al sacramento de la Eucaristía: "Al santísimo Sacramento" (fol. I03); una villanesca (fol. I05), y un tercer romance con idéntico enunciado (fol. I08). Le siguen tres romances más ("A las lágrimas, y arrepentimiento del alma», "Del alma a su Esposo Cristo» y "A 1a Oveja perdida»), concluyendo este romancero con un idilio ("Al alma pecadora»), una canción ("En alabanza del Esposo del alma») y dos romances hagiográficos ("Del Beato Ignacio de Loyola» y "Al seráfico P. S. Francisco"). Se cierra este variado devocionario con el romance "A las llagas de San Francisco», fol. 128, un "Ejercicio de la presencia

1 Recuérdese el soneto (a lo divino): "Pastor que con tus silbos amorosos", incluido en las Rimas sacras (núm. XIV), y a lo profano los sonetos del ciclo de los mansos: "Suelta mi manso, mayoral extraño", "Querido manso mío que venistes" (Rimas, núms. I88, I89). Véase FERNANDO LÁzARO CARRETER, Lope, pastor robado, en Formen der Selbsdarstellung. Festgabe für Fritz Neubert, 1956, pp. 209224, incluido más tarde en Estilo barroco y personalidad creadora, Salamanca, 1966, pp. 173-200.

- "Pie pelicane, Jesu Domine" le denomina Santo Tomás en su himno "Adore Te devote, / latens Deitas». La imagen mitológica del pelicano, presente en los Bestiarios medievales, es dibujada con su pico entre las alas, sacando su propia sangre, con la que alimenta a sus polluelos. El emblema pasó a la heráldica representando la completa abnegación, y es referencia conún en los Cancioneros veligiosos de los siglos Xvi y XvIr. A él alude Ubeda en su Cancionero ( $B A E, \mathrm{XXXV}$, núm. 290). El libro del Fisiologo relaciona a Cristo en la cruz con el pelícano, abierto su costado por una lanzada. Véase al respecto a J. CARMODy, Physiologus latinus $Y$, en University of California Publications in Classical Phylology, XII, 1933. A la misma imagen alude Lope de Vega en su auto sacramental La Santa Inquisición. En sus relaciones con el teatro religioso del Siglo de Oro véase a BRUCE W. WARDROPPER, Introducción al teatro religioso del Siglo de Oro, Madrid, 1967, p. 291 . 
de Dios» (para cada día de la semana), un "Miserere mei Deus» y una "Oratio" como final (fols. I3I, I35, I36).

Los romances eucarísticos, especialmente la villanesca, delatan la técnica de expresar conceptos teológicos en términos de la comedia profana ${ }^{1}$. Los elementos alegóricos y conceptuales están presentados en un tono villanesco y rústico. Las fórmulas narrativas (la iniciación misma) denotan un lenguaje coloquial; humorístico y picaresco. A un "Caballero disfrazado" (la hostia) de atractiva hermosura (en la villanesca al "Santísimo Sacramento») se dirige el rústico de este modo:

Que tenéis cara de Pascua
Me dijo la de Ginés
Como si os hubiera visto
Con vuestra Madre en Belén.
Pues al Sol mira la cara
Buena vista tiene Inés,
Que estando vos de rebozo
No entiendo como la ve.
Porque a quitaros la capa
Toda la Aldea pardiez
Os viera como en el Cielo,
Que fuera mucho de ver.

Se realza el misterio divino de la Transustanciación: la presencia del Dios / Hombre en la hostia, y la creencia a pie juntillas en el sacramento eucarístico: "A pie juntillas lo creo". Se identifica el narrador como villano y le corresponde a éste, y en relación con su estado social, e1 humor, la locuacidad y el desparpajo expresivo:

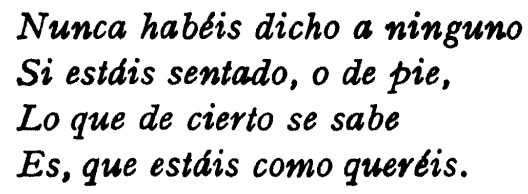

Cristo es por antonomasia el «Caballero de gracia». $\mathrm{Y}$ como tal hace "más gracias que el Papa, / Y más perdones que el Rey». Funde Lope, como

1 J. L. FleCNIAKoska, La formation de l'kauto" veligieux en Espagne avant Calderon, I550-1635, Montpellier, I96r, pp. 309-312. Al auto de Lope de Vega como a una comedia más a lo divino se refiere Fray Modesto de Sanzoles en La alegoria como constante estilistica de Lope de Vega en los Autos Sacramentales, en R. Lit., XVI, 1959, y sobre todo JUAN RODRfGULz-PUERTOLAS, La transposicion de la realidad en los Autos Sacramentales de Lope de Vega, en BH, LXXII, I970, pp. 96-II2. 
vemos, el simbolismo eucarístico (básico en sus Triunphos divinos) con los términos expresivos de los lacayos de la comedia. El mismo título ("Villanesca»), aplicado al Santísimo Sacramento, apunta a la profanidad (metaforismo rural) característica propia de estas fábulas alegóricas.

Fragmentos sacados de varios himnos eucarísticos («Tantum ergo, Sacramentum") se incrustan como textos. Y adquieren una función pedagógica y litúrgica: inculcan la teología de la eucaristía y la veneración de Dios en el pan. Sistemas alegóricos implícitos sostienen las coordenadas narrativas de esta parte: Dios hecho carne (Cristo) se hace esclavo (hostia) y se entrega como pan (comunión), dando así vida (gracia) al hombre. La misma dependencia semántica se establece en la base de los Autos Sacramentales de Lope. E1 signo eucarístico sirve de conclusión apoteósica fijando y gravando en el espectador el símbolo representado ". Tal sucede en el soneto "Cuando en mis manos, Rey eterno os miro" al inculcar la suma veneración y respeto del consagrante ante el misterio eucarístico.

E1 romance "Al Santísimo Sacramento» (fol. I03 v) desarrolla la prerrogativa, también alegórica, de la Eucaristía como total alimento. Si bien pann, éste es celestial: en su confección tomaron parte las mismas "entrañas Virginales / de una soberana Niña». Y aunque esclavo, aleja paradójicamente de los esclavos (pecados) del mundo. Caracteriza al otro romance ("A1 Santísimo Sacramento») la llamada que el alma hace para que sus tres potencias se apresuren a visitar al "estafermo»": al "Dios cubierto, y Dios de Amor", aludiendo el romance al tema calderoniano presente en el auto El gran teatro del mundo:

Múdanse cuantos nacieron
Desde el Rey al labrador,
El que mds poder alcanza
No es mañana lo que es hoy.

Es el oído, expresa el romance, el único sentido que conduce a la presencia divina. Instaura Lope el valor teológico de la palabra (verbum:

1 BRUCE W. WARDROPPER, Introducción al teatro religioso del Siglo de Oro, pp. 275-292.

2 Numerosos poemas dedicados al sacramento de la Eucaristía incluyen los Conceptos espirituales de Alonso de Ledesma. Presentan diálogos, coloquios, villancicos, romances, etc., y como en Lope, sus temas y alegorias sirven de base al desarrollo de varios autos. Sin embargo, las estrofas introductorias se relacionarian con los personajes de la comedia. 
la fe como percepción acústica) y a la vez, subordina diversos procesos sensitivos y plásticos (la vista, el tacto), asentados dentro del escalonado proceso de la teoría del conocimiento de los escolásticos.

Otra área común al Romancero espiritual y a los Autos Sacramentales de Lope es el tema del alma amante; el tema del alma pecadora, descarriada y arrepentida (auto de La adúltera perdonada); el tema del Redentor como "Cordero", como "Pastor" y como "Esposo", presentes en el Cantar de los Cantares (Lope: auto De los Cantares), al igual que las estructuras idílicas del Esposo-Esposa (auto de La Siega), presentes en varios de los romances analizados ${ }^{1}$. El romance "Riéndose va un arroyo, / sus guijas parecen dientes» lo incluye más tarde Lope en su novela La prudente venganza (1624), contrafacta del romance pastoril "Romance del Buen Pastor", y que había sido ddoptado previamente por Valdivielso en su Romancero espiritual ${ }^{2}$.

\section{IV}

Incluye también esta "Tercera parte" del Romancero espiritual, como ya dejamos indicado, dos romances sobre los hechos de varios santos, incluidos anteriormente en las Rimas sacras. Presentan éstas otro romance ("A San Agustín", símbolo del gran arrepentido) que empieza "En las riberas del mar", y en el mismo volumen se incluye el romance "A las llagas de San Francisco" ("Al tiempo que el alma llora»); otro a San Hermenegildo ("Leovigildo, Rey cruel», OS, XIX, p. 299) y, finalmente, otro a Santa Clara. Estas composiciones, tal vez ocasionales (hay también varias glosas y canciones a varios santos), tal vez onomásticas, fueron escritas (seguramente recitadas) con motivo de alguna beatificación o canonización a cuyos festejos estaba siempre

1 Un buen número de los autos de Lope fueron incluidos en las Obras de Lope de Vega (ed. de la Real Acad. Esp., Madrid, pp. 1892-1893, vols. II y III). Muchos de ellos los presenta el vol. XVIII de las OS, Madrid, 1778. Una selección la incluye Nicolás González Ruiz en su edición de Piezas teatrales del teatro teológico español, I. Autos Sacramentales, Madrid, 1968, pp. 73-150.

- Varios romances al Santísimo Sacramento, al igual que a la conversión de San Pablo, a las lágrimas de San Pedro, a la Magdalena, al nacimiento, a la Pasión y muerte de Cristo, inéditos, fueron recogidos por Antonio RodriguezMoñino en Tres cancioneros manuscritos (Poesia religiosa de los Siglos de Oro), en Abaco. Fstudios sobre la literatura española, 2, Madrid, 1969, pp. 127-272. Véase más al respecto en JOsł MARfA DE Cossfo, Observaciones sobre el romancero religioso tradicional, en $B B M P, \mathrm{XXVIII,} \mathrm{1952,} \mathrm{pp.} \mathrm{I66-175.}$ 
listo Lope como mantenedor, empresario o figura pública (el Tomé de Burguillos en el concurso poético celebrado en honor a San Isidro).

Es curioso destacar como la historia hagiográfica se contamina o, más bien adopta el sentido heroico del Romancero histórico:

\author{
No se ha de preciar España \\ De Pelayo ni del Cid. \\ Sino de Loyola sólo, \\ Porque a ser su sol venis.
}

E1 romance "Al Seráfico P. S. Francisco» es una jubilosa invitación ( $A$ A la boda, a la boda / Virtudes bellas, / Que se casa Francisco, / Y ay grandes fiestas") a los desposorios de un "mancebo mercader", quien va a contraer nupcias con dos "hermosas doncellas»: una la humildad, otra la pobreza. Se añade una tercera: la castidad. Cristo es el padrino. Por dote le deja éste sus "cinco llagas»; se hacen las escrituras y firma en sus pies y costado la liquidación de la deuda. Se presenta Francisco como el santo inteligente y joven ("mercader») quien obtiene paradójicas ganancias desposándose con estas tres damas-virtudes: los tres votos constitutivos de su orden mendicante. El plano alegórico se interrelaciona de nuevo con una realidad concreta y profana, pero presentada vívidamente en términos ingeniosos y chocantes.

Los dos romances sobre la Ińfancia de Jesús son los incluidos en la "Primera parte" del Romancero espiritual: "Al Nacimiento de Cristo" (fol. 5) y a "La buena ventura del Niño Jesús» (fol. 8). Y al igual que en los Autos Sacramentales y en el Romancero hagiográfico, traspone Lope el nivel alegórico divino en términos cotidianos: faenas agrícolas y domésticas. Todo se transfigura en el primer romance ante la mágica expectación: los pastores se hallan "soñolientos"; "blanca escarcha" beben sus ovejas y los aullidos de los lobos desafían el ladrar de los mastines. Ha nacido un Dios. Sobrecoge su presencia y mueven a ternura sus delicados pies; alegran sus ojos, vivifica con sus gracias su radiante hermosura ${ }^{1}$. El ángel anuncia la presencia de Dios. La atmósfera evocada es mágica, devota, irreal:

\title{
L.os perros alzan las frentes, $Y$ las ovejuelas corren, Unas por otras turbadas Con balidos desconformes.
}

1..M. Audrey Anron, Cristo en la poesia livica de Lope de Vega, Madrid, 1967, pp. 39-67. 
Al mismo ciclo corresponde el romance "Recién nacido pastor» (OS, XVI, p. 25I) dentro de la temática pastoril y sacra de Los pastores de Belin.

En "Lu buena ventura del Niño Jesús» se relatan las predicciones que una buena gitana va leyendo en la diminuta mano del chiquitín:

\author{
$O$ que rayas tan hermosas \\ $O$ que peregrinas rayas, \\ Corta vida tiene de hombre \\ De Dios la tiene muy larga.
}

Augura la gitana la breve vida del hombre y la eterna de Dios; la redención del viejo Adán con la llegada del nuevo; los llantos de Raquel por la muerte de sus hijos (los Santos Inocentes); 1a huída a Egipto; las enseñanzas en el templo; su persecución, muerte y final resurrección. Compendia el breve romance los dogmas teológicos en torno a la encarnación y a la redención, si bien siguiendo las delgadas rayas que va deletreando la gitana. La buena ventura se transforma en augurio profético; la gitana en divina sibila; la mano en texto y signo gráfico que con gran maestría ésta descodifica. Pero la breve lectura es descifrada en los términos coloquiales de la buena dicción. La Virgen entra en tratos con una gitana; Dios con las artes de la agorera. Y este arte de transponer y simplificar a la vez realidades supremas en términos de lo cotidiano y familiar es único en Lope; singular en sus Autos Sacramentales y no menos en el Romancero espiritual.

El romance "A las lágrimas y arrepentimientos del alma» (fol. IIo) se inserta dentro de la convención poética de "Salid lágrimas» cuyo posible origen sería el soneto de Petrarca "Occhi, piangete; accompagnate il core / Che di vostro fallir morte sostenel. Los famosos versos de la égloga I de Garcilaso ("Salid lágrimas corriendo») aluden a la misma convención. También la canción de Juan Fernández incluida en su Cancionero (ed. de Azáceta, Madrid, I956, p. CXXIII, núm. 862). Y a1 mismo tema ("Ĺágrimas de mi consuelo») alude también Garcí Sánchez de Badajoz en su Cancionero (ed. de I899, p. 49).

Se populariza el tema y se adoptan octosílabos y coplas de pie quebrado (antes liras, cuartetos, cuartetas) a lo Manrique. La composición de Arteaga de Salazar, incluida en el Cancionero de Costantina ("Salid, palabras, temblando») ${ }^{1}$, si bien varía en su formulación inicial, es lugar

1 Recogido en el Pequeño cancionero que se halla en la Biblioteca Nacional de Madrid (núm. 3788), y fue editado recientemente por José María Azáceta en Estudios dedicados a M. Pidal, VII, 1, 1957, pp. 83-I12; CHARLES V. AUBRUN, Salid ldgrimas, en $B H, \mathrm{LX}, 1958, \mathrm{pp}$. 505-112. 
común en Cancioneros y Romanceros sacros ${ }^{1}$. La angustiosa pena por 1a pérdida de la amada ("ausente de Dios») se torna en nostalgia por el perdón divino:

\author{
Pesávale de aver sido \\ Tan ingrata a su Señor, \\ Que perdonada mil veces \\ Otras tantas le ofendió.
}

Como hemos visto, la riqueza de alusiones bíblicas y cristomórficas revelan una amplia cultura religiosa de Lope, recogida seguramente en sus lecturas religiosas: sermonarios, oficio divino, misales, catecismos, etc. Pero la mayoría de las referencias están tomadas de los evangelios, sobre todo de San Juan, San Mateo y San Lucas ${ }^{2}$. A estas fuentes le siguen el Génesis, el Cantar de los Cantares, los Salmos de David, Isaías y Jeremías. Hay una referencia al Levítico $(I, 5)$ en el romance "A la pasión".

Las situaciones bíblicas en torno a la Pasión, sus ámbitos espaciales (de algún modo lingüísticos y alegóricos), figuran en pinturas y en tallas de la época. La composición barroca divide el espacio en varios. planos y perspectivas, establecidas a base de sombras y claroscuros, de enunciaciones pronominales, presentes en este romancero. Nos revela a la vez, no sólo una actitud ascética; también una rica cultura religiosa, saturada de referencias bíblicas, emblemas, símbolos y alegorías. Diariamente, y desde el púlpito, lo mismo que desde el cuadro y desde la talla (Juan Martínez Montañés, Gregorio Fernández, Pedro de Mena) se iba coaccionando al creyente a maneras ascéticas de ser ante la vida en agudo contraste con las apetencias carnales de los sentidos. Tal

1 Es lugar común el tema en pasajes biblicos: «Et egresus foras Petrus flevit amare" (Luc. 22, 62), y sobre la mujer pecadora: ret stans retro secus pedes eius, lacrymis coepit rigare pedes eius (et capillis capitis sui tergebat) (Luc. 7, 38). Populariza ya el tema Luigi Tansillo con su gran poema épico, Le lagrime di San Pietro (1560), compuesto de cuarenta y dos octavas y publicado en I560; reelaborado con novecientas y publicado, en segunda versión, en I585. Fue muy difundido y cré́ numerosos imitadores, entre ellos, Lope, con su extenso romance (aunque de dudosa atribución), titulado "A la negación y lágrimas de San Pedro" ("Contemplativos discursos", OS, XIII, pp. 462-474), y con el romance "Ciuarneciendo el cristal puro" (pp. I35-136) que divide en dos partes, concluyendo cada parte con una breve seguidilla. Véase M. AUDREY AARON, Cristo en la poesía lirica de Lope de Vega, pp. I72-181.

- ARTURo Marfa CaYUera, Los Autos Sacramentales de Lope reflejo de la cultura religiosa del poeta y su tiempo, en Razón y fe, CVIII, I935, pp. I68-190 y; 330-349. 
dialéctica, visual, emotiva, la dramatiza Lope en su Romancero espiritual. En él se desdobla como narrador y como pecador, y escribe un texto dual: literal y semántico; alegórico y anagógico. Pero la voz causativa (la biografiada y la biográfica), sádica a veces, es su núcleo central y genético. Relatando los pasos ascéticos de un pecador ("tú"), narra figurativamente lo cruento de la pasión (exertitium spirituale), llora sus culpas (psicoterapia) y se arrepiente.

Ante el mismo Cristo ( $\mathrm{E} 1$ Cristo de Velázquez») siglos más tarde desgarrará su alma, en voces de angustia, el gran trágico (y no menos comediante) don Miguel de Unamuno. Ya estamos lejos de la cándida sinceridad de Lope. Este, de rodillas ante el retablo sangriento, aceptaba la culpa y lloraba piadosamente la ofensa. Unamuno cuestionará el objeto de la tragedia divina, demandando airado e interrogante (en El Cristo de Velázquez) una justificación a su fe:

\author{
¿En qué piensas Tú, muerto, Cristo mio? \\ ¿Por qué ese velo de cerrada noche \\ de tu abundosa cabelleva negra \\ de nazareno cae sobre tu frente? \\ Miras dentro de $T \hat{i}$, donde esta el reino \\ de Dios, dentro de Ti, donde alborea \\ el sol eterno de las almas vivas.
}

Antonio CARREÑo

University of Illinois 